\title{
Norfolk Terrier
}

National Cancer Institute

\section{Source}

National Cancer Institute. Norfolk Terrier. NCI Thesaurus. Code C53726.

The Norfolk Terrier is among the smallest of the working terriers. It has a short, strong, sturdy body with strongly boned legs and a fox-like muzzle with large solid teeth. The coat is wiry and straight and come in red, wheaten, tan, black and tan, and grizzle occasionally with white markings. The ears are hanging and tight to the cheeks. Height: 10 inches (25 cm.) Weight: 10-12 pounds (4 1/2-5 1/2 kg.) 